\title{
Klinik Araştırma
}

\section{Piriformis Sendromu Tedavisinde Ultrason Eşliğinde Enjeksiyonun Kısa Dönem Etkinliğinin Değerlendirilmesi}

Evaluation of Short-term Effectiveness of Ultrasound-guided Injection in Treatment of Piriformis Syndrome

\author{
Duygu Geler KÜLCÜ ${ }^{1}$, Nilgün MESCİ ${ }^{1}$, Sevilay Çüçen BATIBAY ${ }^{1}$ \\ Aslıhan TARAKTAŞ ${ }^{2}$, İlknur AKTAŞ ${ }^{2}$
}

1. Sağlık Bilimleri Üniversitesi, Haydarpaşa Numune Ĕgitim ve Araştırma Hastanesi, Fiziksel Tıp ve Rehabilitasyon Kliniği 2. Sağlık Bilimleri Üniversitesi, Fatih Sultan Mehmet Eğitim ve Araştırma Hastanesi, Fiziksel Tıp ve Rehabilitasyon Kliniği

\section{$\ddot{O Z E T}$}

Amaç: Piriformis sendromu (PS) olan hastalarda ultrason (US) eşliğinde steroid ve lokal anestezik (LA) enjeksiyonunun kısa dönem etkinliğini değgerlendirmektir.

Yöntem ve Gereçler: Piriformis sendromlu 17 hasta (14/3:kadın/erkek; yaş ortalaması 56.2 \pm 10.2 yıl) çalışmaya dahil edildi. PS tanısı klinik anamnez, piriformis kası üzerinde hassasiyet, Freiberg test, Pace bulgusu ve fleksiyon-adduksiyon-internal rotasyon (FAIR) test sonuçlart ile konuldu. US eşliğinde enjeksiyon öncesi ve enjeksiyondan 1 hafta sonra tedavinin etkinliği; uzun süreli oturma sonrası vizüel ăgrl skalası (VAS: 0-10), piriformis kası üzerinde derin palpasyonla hassasiyet (var) yok), Freiberg testi (pozitif/negatif), Pace bulgusu (pozitif/negatif) ve FAIR testi (pozitif/negatif) ile değerlendirildi. Istatistiksel analizlerde McNemar test ve Wilcoxon test kullanıldı.

Bulgular: VAS ăgrı skorlarının ortalamast 9.2 \pm 1.4 'den $3.7 \pm 0.1$ 'e geriledi $(p<0.001)$. Piriformis kası üzerindeki hassasiyet \%82, Freiberg testi \%80, Pace bulgusu \%75 ve FAIR testi \%82 oranında istatistiksel olarak anlaml derecede negatifleşti $(p<0.001)$.

Sonuç: Ultrason eşliğinde LA ile kombine steroid enjeksiyonu pirifomis sendromlu hastalarda etkili bir tedavi seçeneğidir.

Anahtar Kelimeler: piriformis sendromu; enjeksiyon; ultrason

\section{ABSTRACT}

Objective: The purpose of this study was to evaluate the short-term efficacy of ultrasound (US)-guided steroid and local anaesthetic (LA) injections in patients with piriformis syndrome (PS).

Materials and Method: 17 patients (14/3: female/male; mean age 56.2 years) were diagnosed with PS based on clinical history, tenderness on piriformis muscle, Freiberg test, Pace sign and flexion-adduction-internal rotation (FAIR) test results. Patients who had all tests positive were considered as PS. The therapeutic effect was evaluated at baseline and 1 week after the US-guided injection by visual analog scale (VAS: 0-10) during sitting, tenderness on the piriformis muscle (absent/present), Pace sign (absent/present), Freiberg test (absent/present) and FAIR test (absent/present). Statistical analysis were done with McNemar test and Wilcoxon test.

Results: VAS improved from $9.2 \pm 1.4$ to $3.7 \pm 0.1$ $(p<0.001)$. Tenderness (82\%), Freiberg test (80\%), Pace sign (75\%) and FAIR test (82\%) significantly dissapeared $(p<0.001)$.

Conclusion: US-guided steroid combined with LA injection may be an effective treatment option for patients with PS.

Keywords: piriformis syndrome; injection; ultrasound

Bu çalışma daha önce TURK-MUS-I Multidisipliner Ultrasonorafi Sempozyumunda sözlü bildiri olarak sunulmuştur.
Iletişim Bilgileri

Sorumlu Yazar: Nilgün MESCI

Yazışma Adresi: Haydarpaşa Numune Eğitim ve Araştırma Hastanesi,

Fizik Tedavi ve Rehabilitasyon Kliniği, İstanbul

Tel: +90 (533) 6295998

E-Posta:nilgunbilgili@yahoo.com

Makalenin Geliş Tarihi: 16.11.2016

Makalenin Kabul Tarihi: 03.12.2016 


\section{GíRIŞ}

Piriformis sendromu (PS); piriformis kasinin (PK) hipertrofi, inflamasyon ya da anatomik varyasyonları nedeniyle siyatik sinire kompresyonuyla oluşan nöromusküler bir hastalıktır [1]. PS olan hastalarda sıklıkla siyatalji özelliklerine benzer şekilde ipsilateral kalça, uyluk ve bacakta uyuşma, karıncalanma ve ağrı semptomları görülür [2]. PS'nin herhangi bir ayırıcı klinik bulgusu ya da spesifik tanı kriteri olmadığından teşhisi zordur [3]. Tedavide nonsteroidal antiinflamatuar ajanlar, kas gevşetici ilaçlar, fizik tedavi modaliteleri ve germe egzersizleri önerilebilir. Konservatif tedaviden fayda görmeyen olgularda lokal anestezik ve steroid, botulinum toksin enjeksiyonları yap1labilir [4]. Bu yöntemlerle sonuç alınamayan durumlarda cerrahi uygulanabilir.

Ağrılı bölgeye anatomik landmarkları kullanarak yapılan kör enjeksiyonların yanı sıra elektromiyografi, floroskopi, bilgisayarlı tomografi (BT), manyetik rezonans (MR) ve son y1llarda kullanımı artan ultrasonografi (USG) ile PK lokalizasyonunu doğrulayarak enjeksiyonlar yapılmaktadır [4-7].

Biz de çalışmamızda PS'lİ hastalarda USG eşliğinde gerçekleştirilen lokal anestezik (LA) ve steroid enjeksiyonunun kısa dönem etkinliğini değerlendirmeyi amaçladık.

\section{YÖNTEM ve GEREÇLER}

Çalışmamızda retrospektif olarak Ağustos 2014-Aralık 2015 tarihleri arasında Fizik Tedavi ve Rehabilitasyon polikliniklerimize bașvurmuș ve PS tanısı ile ultrason eşliğinde steroid ve LA enjeksiyonu uygulanmış olan 17 olgu değerlendirildi. Siyatik ağrısı nedeni olabilecek diğer durumlar dișlanarak, PS tanısıyla USG eșliğinde enjeksiyon için yönlendirilmiş hastalar değerlendirildi. Tek taraflı kalça/bacak ağrısı ve PK üzerinde palpasyonla hassasiyeti olan, Freiberg testi (pasif zorlu kalça internal rotasyonunda ağrı), Pace bulgusu (aktif kalça abduksiyon-internal rotasyonuna dirençte ağrı ve güçsüzlük) ve FAIR (fleksiyon, adduksiyon, internal rotasyon) testlerinden en az bir tanesi pozitif olan olgular çalışmaya dahil edildi.

Nörolojik defisiti bulunan, gebelik ya da laktasyon döneminde olan, lumbar ya da kalça bölgesinden geçirilmiş operasyon öyküsü, inflamatuar ya da enfektif hastalığı, kontrolsüz hipertansiyon-diyabeti, kalp/böbrek yetmezliği, kanser hastalığı olan olgular çalıșmaya dahil edilmedi.
USG eşliğinde yapılan enjeksiyonlarda ultrason cihazının (Mindray marka, DC-T6 model, China) 2.5-5 MHz frekanslı konveks probu kullanıldı. Hasta prone pozisyonda iken öncelikle ultrason probu transvers pozisyonda tutularak sakral hiatus belirlendi. Daha sonra prob lateral yönde trokanter majusa doğru hareket ettirildi. PK gluteus maksimus kasinın derininde, medial kenardaki iliumun yüzeyinde görüntülendi (Şekil 1).

Tablo 1: Klinik bulguların tedavi öncesi ve tedavi sonrası karşılaştrılması.

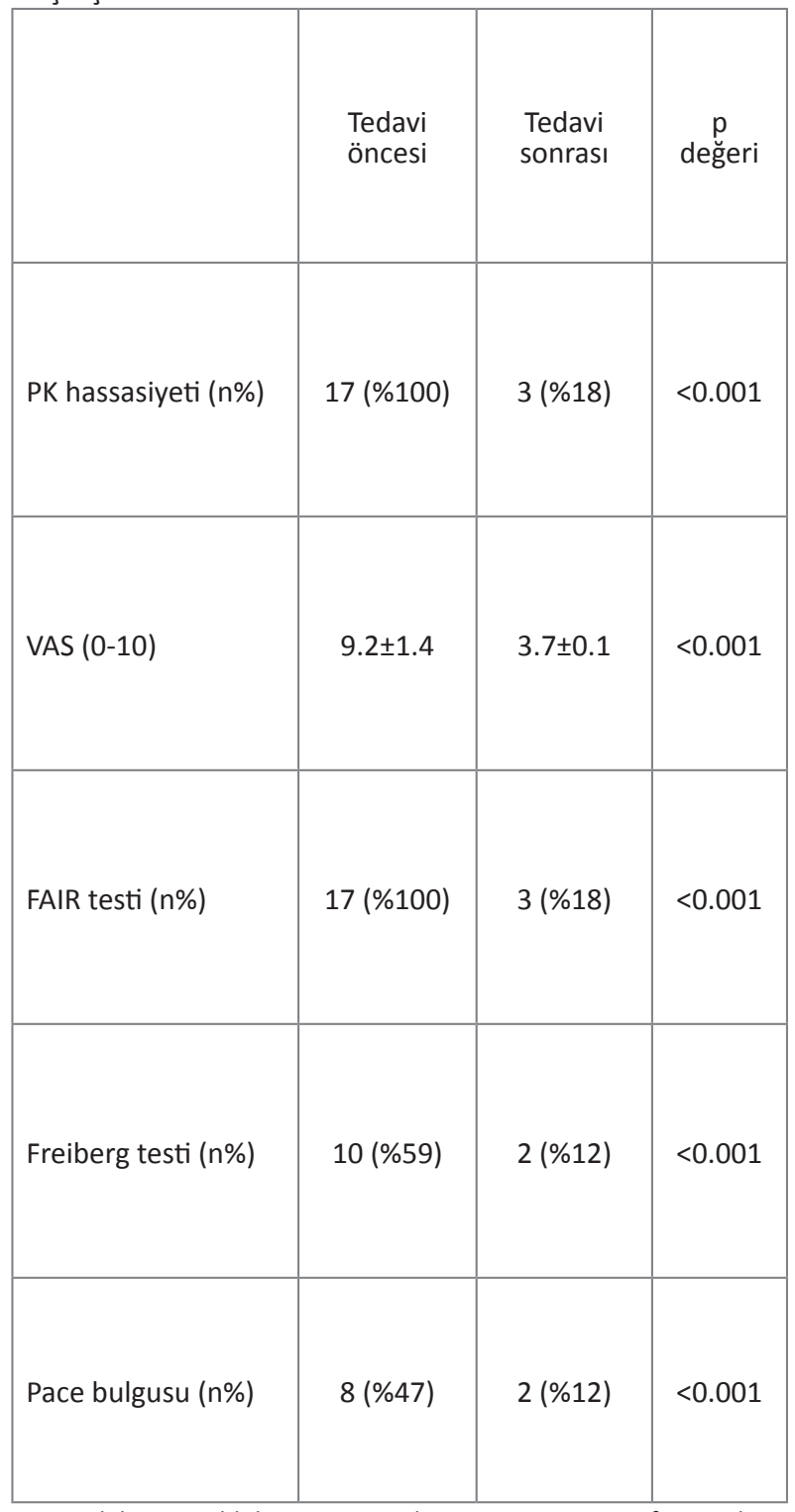

FAIR: Fleksiyon-adduksiyon-internal rotasyon, PK: Piriformis kası, VAS: Vizüel analog skala.

Hastanın kalçası eksternal rotasyona getirilerek kasın hareketi ile PK'nın yeri doğrulandı. 22 gauge iğne ile $45^{\circ}$ açı ile kasın longitudinal aksı boyunca medialden laterale doğru girilerek iğne PK içinde görüntülendiğinde $4 \mathrm{ml} \% 1$ 'lik Prilocain ve $1 \mathrm{ml}$ Betametason kombinasyonu enjekte edildi. Hastalar enjeksiyon öncesi ve enjeksiyondan 1 hafta sonra yapilan kontrol muayenesinde; palpasyonla PK üzerinde hassasiyet, Freiberg testi, Pace bulgusu ve FAIR testi ile değerlendirilmişti. 
Ağr1 değerlendirmesi için 0-10 ölçekli vizüel analog skala (VAS) kullanılmış ve uzun süreli oturma ile kalça ve/veya bacağa yayılan ağn değerlendirilmiști. İstatistiksel değerlendirmede tanımlayıcı istatistiklerin yanısıra bağımlı değişkenler McNemar test ve Wilcoxon test ile analiz edildi.



Şekil 1: Ultrasonografi ile piriformis kasının görüntülenmesi.

\section{BULGULAR}

Çalışmaya dahil edilen 17 olgunun 14'ü kadın, 3'ü erkek ve yaş ortalamaları $56.2 \pm 10.2$ yıl idi. VAS ağrı skorlarının ortalaması enjeksiyon öncesi 9.2 \pm 1.4 'den enjeksiyon sonras1 1 . hafta $3.7 \pm 0.1$ 'e geriledi $(p<0.001)$. Piriformis kas1 üzerindeki hassasiyet \%82, Freiberg testi $\% 80$, Pace bulgusu $\% 75$ ve FAİR testi $\% 82$ oranında enjeksiyon öncesine göre enjeksiyondan 1 hafta sonra istatistiksel olarak anlaml derecede negatifleşti $(\mathrm{p}<0.001)$ (Tablo 1).

Hastalarda enjeksiyon bölgesinde şişlik, kızarıklık, 1sı artışı gibi lokal reaksiyonlar, lokal enfeksiyon, steroid atrofisi, anaflaktik reaksiyonlar, tendon rüptürü ve siyatik sinir hasarı gibi komplikasyonların hiçbiri gözlenmedi.

\section{TARTIŞMA}

Çalışmamızda, USG eşliğinde yapılan LA ve steroid enjeksiyonunun PS'li hastalarda ağrının azaltılmasında etkili bir tedavi yöntemi olduğunu göstermiş olduk. PK sakrum, ilium ve sakroiliak eklem kapsülünden başlayarak büyük siyatik foramenden geçer ve büyük torakanterin superioruna yapışarak sonlanır. Uyluk ekstansiyon ve fleksiyondayken sırasıyla, kalça eklemine dış rotasyon ve abduksiyon yaptırır. PS, siyatik sinirin pelvis çıkışında PK tarafından tuzaklanması ile oluşan klinik tablodur [8]. $\mathrm{Bu}$ tuzaklanma PK'nın uzun süreli veya aşırı kasılması gibi kasın inflamasyonu ve şişmesinden de kaynaklanabilir [9]. Anatomik olarak siyatik sinire yakınlığı nedeniyle de gluteal bölge, kalça ve bacaklarda ağriya neden olur. Hastanın uzun süreli oturması bu ağrının şiddetini arttırır. Ağrı yürümekle ve kalça iç rotasyonu ile gluteal bölge ve uyluk arka yüze yayılır, parestezi de görülebilir. Siyataljinin eşlik ettiği bel ağrısı vakalarının \%6-8'inin PS ile ilişkili olduğu bildirilmiştir [10]. Sakroiliak eklemdeki artritik değişikliklerin PK'ının inflamatuar değişimlerine ve bunun da siyataljiye neden olabileceği ilk defa 1928 y1lında Yeoman tarafindan bildirilmiştir [11]. Günümüzdeki PS tanım1, 1947'de Robinson'un 6 belirgin özelliği tanımlamasıyla başlamıştır; 1) Lokal travma öyküsü, 2) Kalça ve siyatik sinir trasesinde ağr1, yürümede zorluk, 3) Alt ekstremiteyi kaldırma ve eğilme sırasında ağrı ve kalça kaslarını germe sonucu rahatlama, 4) PK'ına derin palpasyonla hassasiyet, kasın sosis şeklinde palpasyonu, 5) Pozitif Lasegue testi, 6) Gluteal atrofi [12].

PS tanıs1 için altın standart bir yöntem yoktur. Siyatalji ve bel ağrisı nedeni olabilecek diğer hastalıklar ekarte edildikten sonra PS düşünülmelidir. Literatür de öncelikle siyatik ağrısının diğer nedenlerinin dişlanması gerektiğini vurgulamaktadır $[13,14]$. Çalışmamızdaki hastaların fizik muayenesinde PK'1 üzerinde derin palpasyonla hassasiyet mevcuttu. Freiberg, Pace ve FAIR testlerinden en az bir tanesi pozitifti. Literatürde bu testlerin hiçbirinin sensivitesi ve spesifitesi açık olarak doğrulanmamaktadır [15]. Ancak tanıya en yardımc1 test olarak FAIR testi ve PK' inda tetiklenmenin pozitif olması önerilmektedir [16].

Siyatalji yapan diğer nedenleri dişlamak için fizik muayeneye yardımcı olarak radyografi, BT, MR ve USG gibi görüntüleme yöntemleri ve elektrofizyolojik testler kullanılabilir. PS tanısında elektrofizyolojik testlerin rolü minimaldır [17, 18]. Ancak radikulopati gibi durumlardan ayırıcı tanının yapılmasinda yardimcidır. Konservatif tedavi modalitelerinden fayda görmeyen hastalarda PK enjeksiyonu yapılabilir. Enjeksiyon kör, stimülatörle veya görüntüleme k1lavuzluğunda teknikler kullanılarak gerçekleştirilebilir. Siyatik sinir ile PK ilişkisinin anatomik varyasyonları nedeniyle enjeksiyon tedavisinde anatomik landmarklar kullanılarak yapılan kör enjeksiyonların yerini floroskopi, BT ve son zamanlarda USG kılavuzluğundaki yöntemlerin aldığını görüyoruz.

Anatomik landmarkların kullanıldığı teknikte enjeksiyonlar sıklıkla elektrofizyolojik stimülatör eşliğinde gerçekleştirilir. Sinir stimülasyonu tekniği ile iğne ucunun kas içinde veya kaslar arasındaki bir düzlemde olup olmadığı güvenilir şekilde ayırt edilemez. 
Kasın direkt görüntülenmesini ve iğnenin doğru pozisyonlandırılmasını sağlayamaması başlıca limitasyonlarıdır [19].

Finnof ve ark. kadavra çalışmasında floroskopi ile kontrast madde enjekte ederek PK ve iğne lokalizasyonu doğruluğunun ancak \%30 oranında sağlanabildiğini gösterdikleri çalışmada USG'nin \%95 doğrulukla validasyonunu bildirmişlerdir [20]. Fabregat ve ark. yaptıkları fizibilite çalışmasında, PS' de botulinum toksin enjeksiyonu için kılavuz olarak kullandıkları USG'nin güvenilirliğini BT ile değerlendirmişler ve USG'nin kolay ulaşılabilir olmas1, radyasyon maruziyetine neden olmaması gibi avantajları ile daha güvenilir ve basit bir prosedür olduğunu belirtmişlerdir [21]. Çalışmamızda USG kılavuzluğunda gerçekleştirdiğimiz PK enjeksiyonlarımızla ağrı veklinik iyileşmede başarılı sonuçlar elde ettik.

Enjeksiyon materyali olarak ise LA, LA+steroid ve botulinum toksin kullanılabilir. LA ve steroid PK enjeksiyonu için en sık kullanılan ilaçlardır. Solüsyon materyali olarak LA'nın uzun etkili steroid ile karışt1r1lmas1 önerilmektedir [22]. Diğer taraftan, Misırlıoğlu ve ark.'nın PS tedavisinde LA ve $\mathrm{LA}+$ steroid enjeksiyonlarını karşılaştırdıkları çalışmada her ikisinin de klinik olarak etkili olduklarını ve birbirlerine üstünlüklerinin olmadığını göstermişlerdir [16]. Çalışmamızda PK' da şişme ve inflamasyona bağlı siyatik sinir tuzaklanması olma ihtimaline karşı enjeksiyon materyali olarak LA + steroid kombinasyonunu kullanmayı tercih ettik.

Çalışmamızın en önemli limitasyonu retrospektif dizayn olmasıdır. Bunun yanında hasta sayısının göreceli olarak az olması ve takip süresinin kısa olması da çalışmanın limitasyonlarıdır.

Sonuç olarak; USG eşliğinde lokal anestezikle kombine steroid enjeksiyonu PS'li hastalarda etkili ve güvenli bir tedavi seçeneğidir.

\section{KAYNAKLAR}

1. Hopayian K, Song F, Riera R, Sambandan S. The clinical features of the piriformis syndrome: a systematic review. Eur Spine J 2010;19:2095-109.

2. Fishman LM, Dombi GW, Michaelsen C, Ringel S, Rozbruch $J$, Rosner B, et al. Piriformis syndrome: Diagnosis, treatment, and outcome - a 10-year study. Arch Phys Med Rehabil 2002;83:295-301.

3. Benzon HT, Katz JA, Benzon HA, Iqbal MS. Piriformis syndrome: anatomic considerations, a new injection technique, and a review of the literature. Anesthesiology 2003;98:1442-8.
4. Hulberta A, Deyleb GD. Differential diagnosis and conservative treatment for piriformis syndrome: a review of the literature. Curr Orthop Pract 2009;20:313-9.

5. Huerto APS, Yeo SN, Ho KY. Piriformis muscle injection using ultrasonography and motor stimulation - report of a technique. Pain Physician 2007;10:687-90.

6. Fanucci E, Masala S, Sodani G, Varrucciu V, Romagnoli A, Squillaci E, et al. CT-guided injection of botulinic toxin for percutaneous therapy of piriformis muscle syndrome with preliminary MRI results about denervative process. Eur Radiol 2001;11:2543-8.

7. Fishman SM, Caneris OA, Bandman TB, Audette JF, BorsookD. Injection of the piriformis muscle by fluoroscopic and electromyographic guidance. Reg Anesth Pain Med 1998;23:554-9.

8. Boyajian-O'Neill LA, McClain RL, Coleman MK, Thomas $P P$. Diagnosis and management of piriformis syndrome: an osteopathic approach. J Am Osteopath Assoc 2008;108:657-64.

9. Solheim LF, Siewers P, Paus B. The piriformis muscle syndrome - Sciatic nerve entrapment treated with section of the piriformis muscle. Acta Orthop Scand 1981;52:73-5.

10. Hallin RP. Sciatic pain and the piriformis muscle. Postgrad Med 1983;74:69-72.

11. Yeoman $W$. The relation of arthritis of the sacro-iliac joint to sciatica, with an analysis of 100 cases. Lancet 1928;212:111923.

12. Robinson D. Piriformis muscle in relation to sciatic pain. Am J Surg 1947;73;355-8.

13. Rodrigue T, Hardy RW. Diagnosis and treatment of piriformis syndrome. Neurosurg Clin N Am 2001;12:311-9.

14. Vandertop WP, Bosma NJ. The piriformis syndrome, a case report. J Bone Joint Surg Am 1991;73:1095-7.

15. Michel F, Decavel P, Toussirot E, Tatu L, Aleton E, Monnier $G$, et al. The piriformis muscle syndrome: an exploration of anatomical context, pathophysiological hypotheses and diagnostic criteria. Ann Phys Rehabil Med 2013;56:300-11.

16. Misirlioglu TO, Akgun K, Palamar D, Erden MG, Erbilir T. Piriformis syndrome: Comparison of the effectiveness of local anesthetic and corticosteroid injections: A double-blinded, randomized controlled study. Pain physician 2015;18:163-71.

17. Jankovic D, Peng P, and Zundert A. Brief review: Piriformis syndrome: Etiology, diagnosis, and management. J Can Anesth 2013;60:1003-12.

18. Jeong HS, Lee GY, Lee EG, Joe EG, Lee JW, Kang HS, Long-term assessment of clinical outcomes of ultrasoundguided steroid injections in patients with piriformis syndrome. Ultrasonography 2015;34:206-10.

19. Peng P, Narouze S. Ultrasound-guided interventional procedures in pain medicine: a review of anatomy, sonoanatomy, and procedures: part I: nonaxial structures. Reg Anesth Pain Med 2009; 34:458-74

20. Finoff JT, Hurdle MF, Smith J. Accuracy of ultrasoundguided versus fluoroscopically guided contrast-controlled piriformis injections: a cadaveric study. J Ultrasound Med 2008;27:1157-63.

21. Fabregat G, Roselló M, Asensio-Samper JM, VillanuevaPérez VL, Martínez-Sanjuan V, Andrés JD, et al. Computer-tomographic verification of ultrasound-guided piriformis muscle injection: a feasibility study. Pain physician 2014;17:507-13.

22. Johansson A, Hao J, Sjolund B. Local corticosteroid application blocks transmission in normal nociceptive $C$-fibres. Acta Anaesthesiol Scand 1990;34:335-8. 